\title{
Dynamic Investigation of a Permanent Magnet Synchronous Motor for Faulty Operations
}

\author{
Muhammed Şeker ${ }^{1}\left(\mathbb{D}\right.$, Duygu Bayram Kara ${ }^{2+}(\mathbb{D}$ \\ ${ }^{1}$ RWTH Aachen University, Faculty of Electrical Eng. and Inf. Tech., Aachen, Germany. (e-mail: muhammed.seker@ rwth-aachen.de). \\ ${ }^{2 *}$ Istanbul Technical University, Electrical Engineering Department, 34469, Maslak, Istanbul, Turkey. (e-mail: bayramd@itu.edu.tr)
}

\section{ARTICLE INFO}

Received: Mar., 05. 2021

Revised: April., 15. 2021

Accepted: May, 24. 2021

\section{Keywords:}

Permanent magnet synchronous motor

Mathematical modelling

Condition monitoring

Demagnetization

Winding degradation

Corresponding author: Duygu Bayram Kara

ISSN: 2536-5010 | e-ISSN: 2536-5134

\section{ABSTRACT}

Industrial efficacy of electrical energy is an important feature for our daily life. To provide efficient and reliable operation, new types of electrical machines and their condition monitoring have gain importance. In this paper, a model based condition monitoring and fault evaluation application for permanent magnet synchronous motors (PMSM) is presented. Possible fault conditions are realized on mathematical model and their results are discussed. In order to observe the dynamic behavior of PMSM, its mathematical model is implemented into MATLAB / Simulink as a reference. Then, faulty conditions are created by altering specific model parameters to imitate possible faults. The behavior of the motor is observed and compared with the reference output to contribute the dynamic effects of faulty operations.

DOI: https://doi.org/10.36222/ejt.891458

\section{INTRODUCTION}

Since electrical machines are the major energy consumer in industry, they should be selected as efficient as possible. Losses of the electrical machines are highly depended on the type and the control equipment for the desired the operation. Therefore, reducing the losses is an important trump to be considered. In the industry servo motors are well-known for the precise move and transportation applications. To determine which type of electrical machines should be selected, the application should have been well arranged. Commonly used types of electrical machines were conventional DC machines, induction machines and synchronous machines in the last century. Since DC motors need brushes and commutator systems, the maintenance becomes problematic. Consequently, brushless motor drive system is selected for servo motor applications due to their robustness and lower maintenance need. These requirements can be met by AC motors or SRM (switched reluctance motor) [1-2]. If desired output torque is expected to be smooth, then induction machine (IM) or synchronous machine (SM) are the candidates. The use of synchronous motors takes place when the constant speed with high reliability is desired with the line frequency. And also, the variable speed drive is possible with inverter-fed systems. Since the permanent magnets (PM) have their own magnetic field due to the material property, in PM motors, dc excitation winding does not be there no longer to create rotor magnetic field. If the PMSM is used then the losses decrease because of brushes, slip rings and dc field winding losses are abolished [3]. The PMSM is newly preferred as a workhorse of the industry because of its advantageous over induction machines (IM) such as:

- PMSM has lower inertia due to the absence of rotor cage, therefore the torque to inertia is higher and this makes the machine response faster than IM.

- The PMSM is more efficient than IM because of the ignorance of rotor copper losses.

- The PMSM has its own excitation due to PM but IM needs a magnetization current to being excited.

- In order to provide same output power, the PMSM will have smaller sizes than IM. If the space is an important parameter to be considered, PMSM should be preferred with its higher power density.

- Since rotor losses is mainly copper losses causing the heating then PMSM is a good selection since its rotor is free from windings.

As a result, PMSM becomes a popular type of electrical machine to be applied in industrial application because of its compactness, efficiency, robustness, reliability, and shape adaptation to working environment [4-6]. From another 
perspective; the general trend in the industry is to reduce environmental impact and to satisfy that new regulations and standards of International Electro Technical Commission (IEC) [7]. PMSM is a good candidate to meet new standards due to its high efficiency, robustness and reliability.

Thus, condition monitoring and fault diagnostics of PMSMs become more important to evaluate and prevent faults which might interrupt the operation. Also, the importance of the PMSM in aerospace and automotive industry increases due to its high reliability [8], therefore it becomes crucial to model and monitor this machine properly. During the monitoring process it is also vital to understand the reason of the faults and any change on the machine's dynamical response caused by them. Therefore, possible faults should be determined and their effects on the machine should be well studied in order to recognize them. In order to monitor the machine condition, parameters such as stator winding resistance and rotor flux linkages are important to be audited. These quantities are also critical for the controller design. Also, obtaining electromagnetic parameters accurately is necessary for applications such as control system design, online fault diagnosis, and condition monitoring.

Electrical machines are the key components to couple electrical and mechanical power; therefore, their faults can be occurred on both sides. For the electrical side, PMSM has stator windings and rotor magnets. Stator windings can be open circuited due to loss of connection of windings or short circuited due to dysfunctionality of the isolation. According to Reference [9], 35-40\% of the PMSM faults are reasoning from the stator faults [10]. The common stator windings faults are because of isolation depreciation causing inter-turn faults. These can lead to huge problems such as phase-to-ground faults. Also Reference [11] indicates that the phase-to-phase or phase-to-ground faults are the ultimate result of undetected turn-to-turn faults, as a general belief. The failure of the insulation is modelled as a resistance, named as fault resistance $\left(\mathrm{r}_{\mathrm{f}}\right)$ and its value is dependent on the severity of the fault. The value of the resistance changes rapidly from infinity to zero in the cases of short circuit. The resistance is tuned to infinity for no fault operation. For the short-circuit the value of the resistance decreases rapidly to zero by indicating the fault severity through its amplitude [12]. Whenever $r_{f}$ equals to zero, the windings are assumed to be fully short circuited.

Another fault possibility is the demagnetization which is caused by the stator field. In other words, rotor magnets can be demagnetized due to the high opposite magnetization caused by the stator magnetic field. Another reason for demagnetization in PMSM is the high temperature on magnets. Especially for the surface mounted PMSMs, magnet is exposed to higher flux harmonics causing temperature increase. And also for the super and under synchronous operations rotor is subjected to hysteresis and eddy-current losses resulting additional temperature rise [13]. References [14] and [15] have investigated PMSMs with partially demagnetized magnets at certain rates. Since the demagnetization of the magnets can lead to flux disturbances, unbalanced magnetic pulls (UMP) occurs resulting in the vibration and noise [16].

Additionally, dynamic problems might also occur due to torque pulsations. From the mechanical aspect, bearing damage and eccentricity are the possible faults for PMSM [17-18]. The bearing fault is a common problem for all rotating systems. Another important but not so often confronted rotor fault is the broken or cracked magnets on the rotor.
Lastly, to support line-start ability of PMSMs a cage arrangement can be implemented to rotor. For this case, PMSMs can be supplied directly from the network. This brings a possibility of having some imbalances on the supply side such as frequency and voltage fluctuations.

In this study, mathematical model response two common fault modes are investigated. First, a PMSM model is created on Matlab / Simulink environment and a reference operation is defined for motor. Then failure modes are realized through the intentional manipulations of relevant parameters. The resulting dynamic outputs are compared with the reference case in terms of amplitudes.

\section{MATHEMATICAL MODEL FOR PMSM}

To model a PMSM dq0 transformation, known as Park's transformation, is used for linear representation of rotating quantities. This transformation fixes the reference frame to the rotor and all electrical quantities are assumed to rotate with the rotor angular speed. This methodology brings simplicity due to decrease 3-phase stator system into 2-phase system which means stator will have only one set of two windings. Since the rotor has only magnets, they can be modelled as current or flux linkage sources. When the transformation is done and fictitious set of direct and quadrature windings are set to represent stator windings, no varying inductance is obtained.

Dynamic model is derived under these assumptions [19].

The saturation and parameter changes are neglected.

The inductance versus rotor position is sinusoidal.

The stator windings are balanced with sinusoidal distributed magneto-motive force.

First, the stator voltages should be transformed into dq0frame with the transformation matrix given in Eq. 1 .

$$
\left[\begin{array}{l}
v_{q} \\
v_{d} \\
v_{0}
\end{array}\right]=\frac{2}{3}\left[\begin{array}{ccc}
\cos (\theta) & \cos \left(\theta-\frac{2 \pi}{3}\right) & \cos \left(\theta+\frac{2 \pi}{3}\right) \\
\sin (\theta) & \sin \left(\theta-\frac{2 \pi}{3}\right) & \sin \left(\theta+\frac{2 \pi}{3}\right) \\
1 / 2 & 1 / 2 & 1 / 2
\end{array}\right]\left[\begin{array}{c}
v_{a} \\
v_{b} \\
v_{c}
\end{array}\right]
$$

Voltage stator equations presented in rotor reference frame are given in Eq. 2 where $R_{s}$ is stator resistance, $\lambda_{a f}$ is the mutual flux between armature and field windings, $\omega_{r}$ is the rotor angular speed, $L_{d}$ and $L_{q}$ are the direct and quadrature axis inductances, respectively.

$$
\left[\begin{array}{c}
v_{q s}^{r} \\
v_{d s}^{r}
\end{array}\right]=\left[\begin{array}{cc}
R_{s}+L_{q} p & \omega_{r} L_{d} \\
-\omega_{r} L_{q} & R_{s}+L_{d} p
\end{array}\right]\left[\begin{array}{c}
i_{q s}^{r} \\
i_{d s}^{r}
\end{array}\right]+\left[\begin{array}{c}
\omega_{r} \lambda_{a f} \\
0
\end{array}\right]
$$

By transferring these equations to Laplace domain, Eq. 3 and Eq. 4 can be obtained;

$$
\begin{gathered}
v_{q s}^{r}=\left(R_{s}+L_{q} s\right) i_{q s}^{r}+\omega_{r} L_{d} i_{d s}^{r}+\omega_{r} \lambda_{a f} \\
v_{d s}^{r}=-\omega_{r} L_{q} i_{q s}^{r}+\left(R_{s}+L_{d} s\right) i_{d s}^{r}
\end{gathered}
$$

Currents can be derived from the previous equations in well-known Laplace forms in Eq. 5 and Eq. 6.

$$
i_{q s}^{r}=\frac{1}{L_{q}} \frac{v_{q s}^{r}-\omega_{r} L_{d} i_{d s}^{r}-\omega_{r} \lambda_{a f}}{\left(s+R_{s} / L_{q}\right)}
$$




$$
i_{d s}^{r}=\frac{1}{L_{d}} \frac{v_{d s}^{r}+\omega_{r} L_{q} i_{q s}^{r}}{\left(s+R_{s} / L_{d}\right)}
$$

Flux linkages for direct and quadrature axes calculated through current expressions are given in Eq. 7 and Eq. 8.

$$
\begin{gathered}
\lambda_{q s}^{r}=L_{q} i_{q s}^{r} \\
\lambda_{d s}^{r}=L_{d} i_{d s}^{r}+\lambda_{a f}
\end{gathered}
$$

For these quantities, electromagnetic torque is given in Eq. 9 through mechanical and electrical approaches while $J$ is the moment of inertia, $B$ is the damping coefficient and $T_{l}$ is the load torque [20].

$$
T_{e}=\frac{3}{2} \frac{P}{2}\left[\lambda_{d s}^{r} i_{q s}^{r}-\lambda_{q s}^{r} i_{d s}^{r}\right]=\omega_{m}(J s+B)+T_{l}
$$

\section{REFERENCE DYNAMIC MODEL OF PMSM}

In order to evaluate dynamic behavior of PMSM with various faults, a reference operation should be defined. For this purpose, a $220 \mathrm{~V}, 50 \mathrm{~Hz}, 8$ poles surface mounted PMSM with stator resistance $2.875 \Omega$, direct and quadrature inductances 8.8 $\mathrm{mH}$, mutual flux linkage $0.175 \mathrm{~Wb}, 0.0008 \mathrm{~kg} . \mathrm{m} 2$ moment of inertia is observed. First a reference operation is executed to compare with faulty cases. The dynamic answers of chosen PMSM for $10 \mathrm{Nm}$ load torque are given in Fig. 1 - 3.

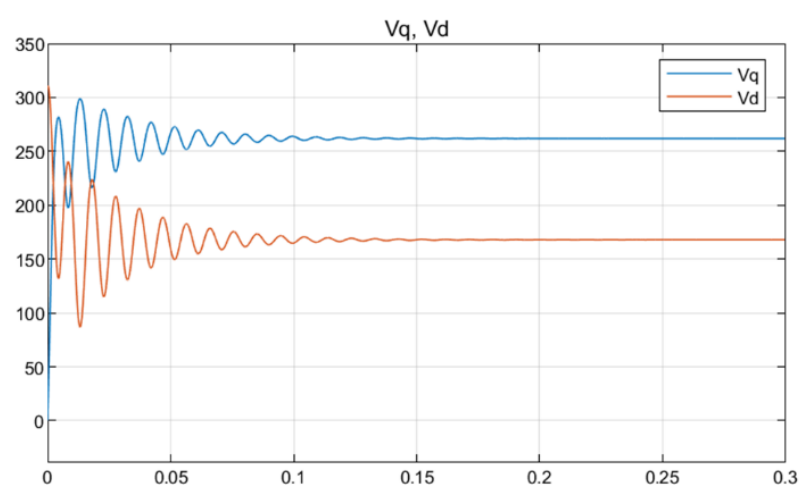

Figure 1. Voltages for direct and quadrature axes.

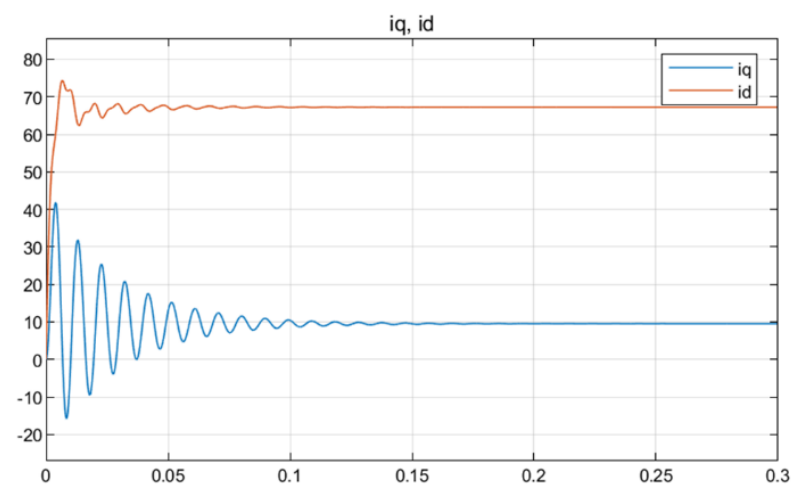

Figure 2. Currents for direct and quadrature axes.

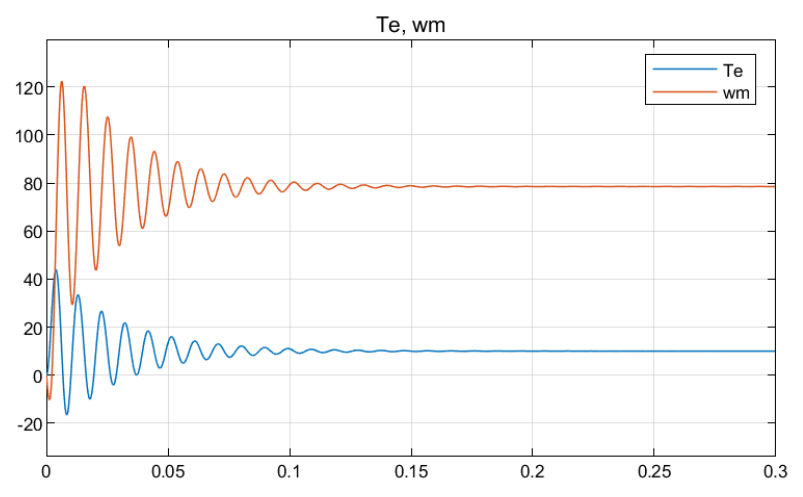

Figure 3. Shaft Torque and speed.

\section{IMPLEMENTATION OF FAILURE MODES}

It has already been mentioned above that one of the major faults occur on the stator as inter-turn fault and it can be modelled as a drop in the resistances. On the other hand, to imitate the demagnetization, the mutual flux linkage between rotor magnets and stator armature winding $\lambda_{\text {af }}$ can be limited. From that point of view, there are two main parameters to be changed along the simulation. There may be some other results for the aforementioned faults. In other words, some consequences should be taking into account as the side effects of these alterations in experimental studies.

1. Stator resistance has a direct relation with the increase of temperature, and it will affect the system,

2 . The magnetic flux linkages variation changes the torque production and also the speed of the machine.

However, in this study these possibilities have been ignored because of the mathematical model limitations.

With the changing of aforementioned parameters, the faulty cases are realized and the machine's dynamical responses are obtained and evaluated regarding the created scenarios. Two different failure modes (FM) are realized and their dynamical behaviors are monitored.

The FMs are listed below:

- Winding degradation: Decrease in the stator resistance to simulate short circuits in various percentages,

- Partial Demagnetization: Decrease in the flux linkage to imitate partial demagnetization resulted from a cracked magnet.

To compare the faulty operations voltage $\left(\mathrm{v}_{\mathrm{d}}\right.$ and $\left.\mathrm{v}_{\mathrm{q}}\right)$ and current $\left(I_{d}\right.$ and $\left.I_{q}\right)$ are shared for the constant torque and speed ( $\mathrm{T}$ and $\omega)$.

\subsection{Failure mode 1: winding degradation}

Regarding Table I; with the decrease of stator resistance the current of direct axis increases as an expected result. Also, $\mathrm{v}_{\mathrm{q}}$ increases while $v_{d}$ decreases. In other words, for the higher percentages of short circuit, balance between the voltages of direct and quadrature axis changes while their vector sum converges approximately to the same values. Also, time to reach the steady state strings out with the decreased resistance. As the short circuit percentage augments, the longer time requires to achieve steady state operation. Furthermore, the oscillations enlarge for all parameters. 
TABLE I

RESULTS FOR FAILURE MODE 1: DECREASE IN THE STATOR RESISTANCE VALUE

\begin{tabular}{cccccc}
\hline \hline & Case 1 & Case 2 & Case 3 & Case 4 & Case 5 \\
\hline Stator Resistance - $\mathrm{R}_{\mathrm{s}}$ & 2.875 & 2.15 & 1.4375 & 0.71875 & 0.2875 \\
$\mathrm{~V}_{\mathrm{q}}$ & 261.9 & 278.7 & 295.7 & 308.4 & 311.1 \\
$\mathrm{~V}_{\mathrm{d}}$ & 167.9 & 138.2 & 96.78 & 40.98 & 1.8 \\
$\mathrm{I}_{\mathrm{d}}$ & 67.25 & 76.12 & 85.02 & 92.35 & 94.88 \\
$\mathrm{I}_{\mathrm{q}}$ & 9.524 & 9.524 & 9.524 & 9.53 & 9.569 \\
\hline \hline
\end{tabular}

\subsection{Failure mode 2: partial demagnetization}

Table II shows that current components elevate with the decreasing rotor mutual flux linkage to satisfy required magnetic coupling and to induce defined electromagnetic torque. There is no significant alteration on the voltage values since the relevant modification is not defined on the electrical circuit as the previous one.

TABLE II

RESULTS FOR FAILURE MODE 2: CHANGE IN THE FLUX LINKAGE OF ROTOR AS DEMAGNETIZATION

\begin{tabular}{cccccc}
\hline \hline & Case 1 & Case 2 & Case 3 & Case 4 & Case 5 \\
\hline $\begin{array}{c}\text { Rotor Mutual Flux Linkage } \\
\left(\lambda_{\mathrm{af}}\right)\end{array}$ & 0.175 & 0.1575 & 0.14 & 0.1225 & 0.105 \\
$\mathrm{Vq}$ & 261.9 & 262 & 262.6 & 264.1 & 266.7 \\
$\mathrm{Vd}$ & 167.9 & 167.8 & 166.8 & 164.5 & 160.2 \\
$\mathrm{Id}$ & 67.25 & 68.19 & 69.07 & 69.84 & 70.45 \\
$\mathrm{Iq}$ & 9.524 & 10.58 & 11.9 & 13.61 & 15.87 \\
\hline \hline
\end{tabular}

\section{CONCLUSION}

In this study, the dynamical modelling of a PMSM is achieved and its fault evaluation is executed. The rotor reference frame is employed for the modelling to calculate $\mathrm{d}$ - and q- axes voltage. Different failure modes are presented and their dynamic results are compared with the reference model. Deliberate manipulations of parameters cause the dynamic model to respond different to satisfy torque and speed which are hold constant.

In order to imitate short circuit failure, stator resistance value is decreased in different percentages. For this fault mode, the oscillation interval and damping time increases during the start, by the augmented winding degradation. To simulate the demagnetization or broken magnet failure, rotor flux $\lambda_{\mathrm{af}}$ is decreased gradually. The torque and speed characteristics do not show a noticeable difference but the higher damping times are observed. Also the stator current components raise to provide the required coupling field.

These findings lead the researcher of diagnosing;

1. Winding degradation fault while monitoring longer time to reach steady state operation and larger oscillations with unexpected increase in the direct axis current.

2. Demagnetization fault while monitoring increasing current components with slightly lengthened out time to reach steady state.

As the contribution, dynamic investigation of faulty operations is guiding for the condition monitoring purposes. A condition monitoring list is possible to be presented by creating different scenarios through the manipulations of relevant machine parameters. As the future work, authors are planning on correlating the dynamical model result with the experimental observations.

\section{REFERENCES}

[1] M. Yıldırım and H. Kurum, "Influence of Stator Embrace on Torque of In-Wheel Switched Reluctance Motor," European Journal of Technique (EJT), vol.7, no.2, pp. 78-84, 2017.

[2] E. Kılıç, S. Şıt, H. Özçalık and A. Gani, "An Efficient Adaptive Controller Design for Three Phase Induction Motors based on RBF Neural Network.", European Journal of Technique (EJT), vol. 7, no. 1, pp. 69-77, 2017.

[3] R. Krishnan, "Application Characteristics of Permanent Magnet Synchronous and Brushless dc Motors for Servo Drives," IEEE Trans. Ind. Appl. vol. 27, pp. 986-996, 1991.

[4] M. A. Rahman and P. Zhou, "Analysis of Brushless Permanent Magnet Synchronous Motors," IEEE Trans. on Ind. Electronics, vol. 43, no.2, pp. 256-267, 1996.

[5] H. Yetiş, and T. Göktaş, "Comparative Design of Permanent Magnet Synchronous Motors for Low-Power Industrial Applications," Balkan Journal of Electrical and Computer Engineering, vol, 8, no. 3, pp. 218224, 2020.

[6] A. Consoli, G. Scarcella, and A. Testa, "Industry application of zerospeed sensorless control techniques for PM synchronous motors," IEEE Trans. Ind. Appl., vol. 37, pp. 513-521, 2001.

[7] D. Gatt, C. Yousif, M. Cellura and L. Camlleri, "An Innovative Approach to Manage Uncertainties and Stock Diversity in the Epbd Cost-Optimal Methodology," European Journal of Technique (EJT), vol. 8, no.1, pp. 35-49, 2018.

[8] S. Bolognani, M. Zordan, and M. Zigliotto, "Experimental fault-tolerant control of a PMSM drive,” IEEE Trans. Ind. Electron, vol. 47, pp. 1134 1141, 2000.

[9] S. S. Kulkarni and A.G. Thosar, "Mathematical Modeling and Simulation of Permanent Magnet Synchronous Machine," Int. J. Electron. Electr. Eng., vol. 1, pp. 66-71, 2013.

[10] Z. Doğan and R. Selçuk, "A Diagnosis of Stator Winding Fault Based on Empirical Mode Decomposition in PMSMs.," Balkan Journal of Electrical and Computer Engineering, vol. 8, no. 1, pp. 73-80, 2020.

[11] G. B. Kliman, W. J. Premerlani, R. A. Koegl and D. Hoeweler, "A new approach to on-line turn fault detection in AC motors," presented at 1996 IEEE Industry Applications Conference $31^{\text {st }}$ IAS Annual Meeting, San Diego, CA, USA, 2002.

[12] B. Vaseghi, N. Takorabet, B. Nahid-Mobarakeh and F. Meibody-Tabar, "Modelling and study of PM machines with inter-turn fault dynamic model-FEM model,” Electr. Power Syst. Res., vol. 81, pp. 1715-1722, 2011.

[13] D. D. Reigosa, F. Briz, P. García, J. M. Guerrero and M. W. Degner, "Magnet temperature estimation in surface PM machines using highfrequency signal injection," IEEE Trans. Ind. Appl., vol. 46, pp. 1468$1475,2010$.

[14] Z. Yang, X. Shi and M. Krishnamurthy, "Vibration monitoring of PM synchronous machine with partial demagnetization and inter-turn short circuit faults" presented at IEEE Transportation Electrification Conference and Expo (ITEC), Detroit, MI, USA, 2014.

[15] W. Le Roux, R. G. Harley, and T. G. Habetler, "Detecting rotor faults in low power permanent magnet synchronous machines," IEEE Trans. Power Electron., vol.22, pp. 322-328, 2007.

[16] M. Zafarani, T. Goktas and B. Akin, "A Comprehensive Magnet Defect Fault Analysis of Permanent-Magnet Synchronous Motors," IEEE Transactions on Industry Applications, vol. 52, no.2, pp. 1331-1339, 2016.

[17] M. Riera-Guasp, J. A. Antonino-Daviu, and G. A. Capolino, “Advances in electrical machine, power electronic, and drive condition monitoring and fault detection: State of the art," IEEE Trans. Ind. Electron., vol. 62, pp. 1746-1759, 2015.

[18] J. Hong et al., "Detection and Classification of Rotor Demagnetization and Eccentricity Faults for PM Synchronous Motors," IEEE Transactions on Industry Applications, vol. 48, no. 3, pp. 923-932, 2012.

[19] Krishnan, R. Permanent magnet synchronous and brushless DC motor drives, CRC press, USA, 2009.

[20] M. Döşoğlu and M. Dursun, "Response and Analysis of Permanent Magnet Synchronous Motor According to Different Reference Signals," Balkan Journal of Electrical and Computer Engineering, vol. 6, pp. 1822, 2018. 


\section{BIOGRAPHIES}

Muhammed Seker obtained his BSc degree in electrical engineering from Istanbul Technical University (ITU) in 2019. He is currently studying as Master Student in the RWTH Aachen University in the Faculty of Electrical Engineering and Information Technology. He is pursuing his master's in Electrical Power Engineering. His research interests are electrical drive systems and their control and monitoring, energy storage systems and their applications.

Duygu Bayram Kara obtained her B.Sc., M.Sc., and Ph.D. degrees from the Electrical and Electronics Faculty of Istanbul Technical University (ITU), in 2006, 2009, and 2015, respectively. She worked as Research Assistant in ITU between 2007 and 2015. She joined University of Tennessee Knoxville, Nuclear Engineering Department and Maintenance and Reliability Centre, as a Visiting Researcher, for induction motor diagnostic studies in 2013. She is currently working as Assistant Professor in the Electrical Engineering Department, ITU. Her research interests include technical design and dynamics of electrical machines, additionally their condition monitoring and fault detection through signal processing and soft computing algorithms. 